\title{
Occupational Exposure to Sharp Instrument Injuries among Dental, Medical and Nursing Students in Mahatma Gandhi Mission's Campus, Navi Mumbai, India
}

\author{
Juveria Syed Ali Hussain, Sabita M Ram, Jyotsna Galinde, Ranganatha Rao K Jingade
}

\begin{abstract}
Background: Sharp instrument injuries among health care students significantly increase the risk of transmission of different blood-borne pathogens which can lead to serious consequences including death.
\end{abstract}

Objectives: The study was carried out to determine the prevalence and factors associated with sharp instrument injuries among the health care students in the Mahatma Gandhi Mission's Campus, Navi Mumbai and to make recommendations to the institutional authorities about measures to be undertaken to prevent such injuries among the students.

Materials and methods: A cross-sectional questionnaire study was conducted among 700 health care students which included dental, medical and nursing students during their clinical training at Mahatma Gandhi Mission's Campus, Navi Mumbai from May 2012 to July 2012. It was a self-administered questionnaire with a 1-year recall period for sharp instrument injury. The data was analyzed using descriptive statistics and Chi-square test.

Results: The questionnaire was completed by 627 students of which $76.4 \%$ of nursing, $75.4 \%$ of dental and $48.7 \%$ of the medical students had experienced sharp instrument injuries in the past 1 year with hollow-bore needle being the most common instrument causing such injuries. Overall, $77.4 \%$ of the students had not reported the incident of the injury and only $34.4 \%$ of the students had taken postexposure prophylaxis.

Conclusion: Educational interventions with effective training on proper handling and disposal of sharp instruments and postexposure prophylaxis along with the formation of a reporting center are some of the recommendations which can reduce the occupational exposure to sharp instrument injuries among the health care students.

Keywords: Injuries, Sharp instruments.

How to cite this article: Hussain JSA, Ram SM, Galinde J, Jingade RRK. Occupational Exposure to Sharp Instrument Injuries among Dental, Medical and Nursing Students in Mahatma Gandhi Mission's Campus, Navi Mumbai, India. J Contemp Dent 2012;2(2):1-10.

Source of support: Nil

Conflict of interest: None declared

\section{INTRODUCTION}

Health care students are exposed to a number of occupational hazards in a work place. There is a high-risk of exposure to pathogens among the health care students while they become involved in patient's investigation and treatment during their clinical training. There is a risk of transmission of more than 20 different blood-borne pathogens through percutaneous injuries of which the most commonly transmitted pathogens are hepatitis B virus (HBV), hepatitis C virus (HCV) and human immunodeficiency virus (HIV). ${ }^{1,2}$ Occupational exposure to percutaneous injuries, such as needle stick and other sharp instruments injuries, are an important concern for health care students. According to the World Health Organization (WHO), approximately three million individuals are injured annually due to needle stick or sharp injuries. ${ }^{3}$ The risk of transmission from infected persons to nonimmune persons through a percutaneous (needles stick/sharp instrument) injury has been estimated to be 6 to $30 \%$ for HBV, 5 to $10 \%$ for $\mathrm{HCV}$ and $0.3 \%$ for HIV. ${ }^{4}$

A sharp injury (SI) is defined as 'the par literal introduction into the body of a health care worker, during the performance of his other duties, of blood or other potentially infectious material by a hollow-bore needle or sharp instrument, including but not limited to needles, lancets, scalpels and contaminated broken glass' (Fig. 1). ${ }^{5}$ Sharp instrument injuries are a biological hazard for health care students which can occur during a variety of procedures, such as needle recapping, handling/transferring instruments, during blood collection or intravenous line administration, needle disposal, wound suturing and other such procedures.

Data from the EPINET system suggest that in an average hospital, workers incur approximately 27 needle-stick injuries/100 beds/year. ${ }^{6}$ However, as data about occupation

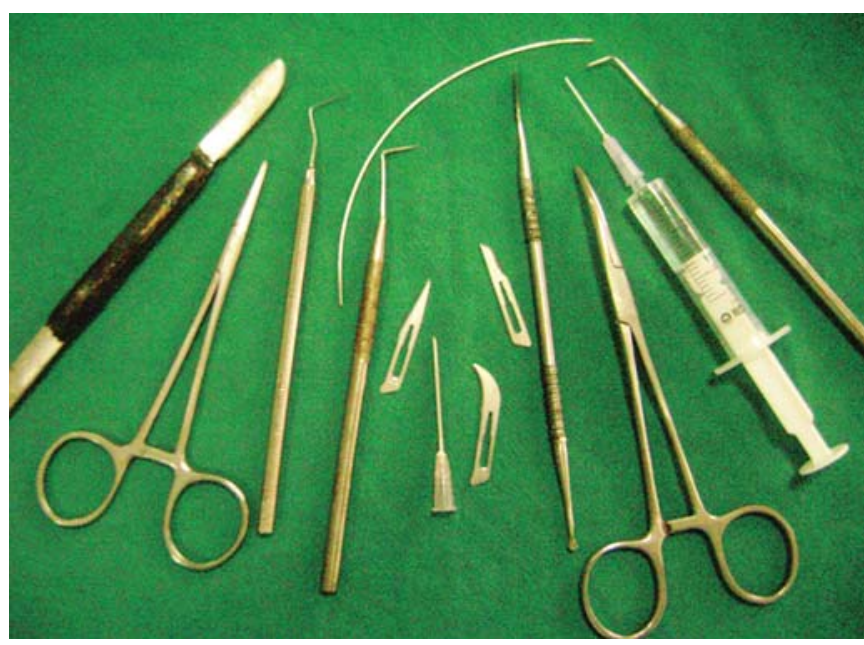

Fig. 1: Sharp instruments 
related injuries is scarce in India, it is not known exactly how many such injuries occur each year which makes it impossible to estimate an annual incidence. ${ }^{7,8}$ Also, underreporting of sharp instrument injuries and poor surveillance systems have led to lack of substantial data describing the exact magnitude of these incidents in the country.

No data was currently available on the occupational exposure to sharp instrument injuries among dental, medical and nursing students in the Mahatma Gandhi Mission's Campus, Navi Mumbai. Preventing such injuries is an essential part of any blood-borne pathogen prevention program in the institution. The present study addressed the important issue of sharp instrument injuries among different categories of health care students which included medical, dental and nursing students, the various factors responsible, the circumstances under which these injuries occur and the measures to be undertaken to prevent such injuries through improvement in knowledge, attitude and practice.

\section{AIM AND OBJECTIVES}

\section{Aim}

The aim of this study was to assess the occupational exposure to sharp instrument injuries among medical, dental and nursing students in Mahatma Gandhi Mission's Campus, Navi Mumbai, India.

\section{Objectives}

The objectives of this study were as follows:

1. To determine the demographic profile of all health care students in Mahatma Gandhi Mission's Campus.

2. To determine the prevalence of sharp instrument injuries in terms of cases and episodes among dental, medical and nursing students.

3. To determine the procedures and instruments, such as hollow-bore needle, suture needle, intravenous catheters, scalers, burs, orthodontic wires and scissors causing sharp instrument injury among dental, medical and nursing students.

4. To assess the rate of reporting and the management of sharp instrument injuries among all the health care students.

5. To evaluate the knowledge about sharp instrument injuries and protective measures taken to prevent such injuries among all the health care students.

6. To make recommendations to the institutional authorities about measures to be initiated to reduce such sharp instrument injuries among the health care students.

\section{MATERIALS AND METHODS}

This survey was a cross-sectional study which was carried out among 700 health care students during their clinical training at Mahatma Gandhi Mission’s Campus, Navi Mumbai from May 2012 to July 2012. The health care students included in this study were medical, dental and nursing students respectively. The proposal, including ethical views was approved by the Ethics Committee. The study consisted of a self-administered questionnaire adapted from a previous survey instrument. ${ }^{9}$ A 1-year recall period was used throughout the questionnaire. In this study, sharp instruments included hollow-bore needle, suture needle, intravenous catheters, scalpels and scissors. Cases of sharp instrument injuries were the number of participants who had at least one experience of such injuries and the episodes were the number of injuries that were experienced by the participants.

The participants were informed about the purpose of the study and a written consent was obtained from them. The questionnaire was pretested on a random sample of 65 participants to ensure predictability, validity and interpretation of responses. The reliability of the questionnaire was assessed using Cronbach's alpha $(\alpha=0.831)$. Strict confidentiality of the participant's information and responses was ensured and the filled questionnaire was collected on the same day which was then subjected to statistical analysis.

\section{STATISTICAL ANALYSIS}

The data was presented using frequency tables, descriptive statistics and graphs. Further statistical analysis was done using Chi-square test for association between attributes. The analysis was performed using statistical package for social sciences, SPSS, version 17. Alpha was set at 5\% level.

\section{RESULTS}

Demographic profile: Of the 700 questionnaires, 627 (89.5\%) were completed and returned. Among the 627 participants, 306 (48.8\%) were dental students, 232 (37\%) were medical students and 89 (14.2\%) were nursing students. The mean age in years was 22.17 ( \pm standard deviation, 1.870) among the students. The sex distribution among the health care students revealed that (474/627) 75.6\% were females and 153 (24.4\%) were males (Table 1).

\section{PREVALENCE OF SHARP INSTRUMENT INJURIES}

During the clinical training in the past 1 year, 412/627 (65.7\%) were the cases of sharp instrument injuries among dental, medical and nursing students respectively.

\section{Dental Students}

Out of 231/306 (75.4\%) of the dental students had experienced sharp instrument injuries in the past 1 year. 
Majority 80/231 (34.6\%) of the episodes of sharp instrument injuries were more than two, followed by 76/231 (32.9\%) of one episode and 75/231 (32.4\%) of two episodes of such injuries were reported (see Table 1).

\section{Medical Students}

Among the medical students, $113 / 232$ (48.7\%) had experienced sharp instrument injuries in the past 1 year. Two episodes of such injuries were reported by 47/113 $(41.5 \%)$ of the medical students followed by 44/113(38.9\%) episode of one injury and 22/113 (19.4\%) reported of more than two episodes respectively (Table 1$)$.

\section{Nursing Students}

Of the 89 nursing students who participated in this study, $68 / 89$ (76.4\%) were the cases of sharp instrument injuries in the past 1 year. Two episodes of the injury were commonly reported by 41/68 (60.2\%) of the nursing students followed by 15/68 (22\%) of one episode and 12/68 (17.6\%) of more than two episodes respectively. (Table 1)

\section{PROCEDURE AND INSTRUMENTS CAUSING SHARP INJURIES}

\section{Dental Students}

In the present study, 121/231(52.3\%) of the sharp instrument injuries among the dental students occurred during administration of local anesthetic injection followed by 65/ 231 (28.1\%) while handling instruments and 38/231 (16.4\%) during scaling and polishing (Table 2). Majority of the sharp instrument injuries 162/231 (70.1\%) were commonly caused by hollow-bore needle followed by 134/231 (58\%) of the injuries by scalers and 70/231 (30.3\%) by orthodontic wire respectively (Fig. 2).

\section{Medical Students}

Among the medical students, intramuscular or intravenous injection was found to be most common procedure associated with 70/113 (61.9\%) sharp instrument injuries followed by $21 / 113$ (18.5\%) injuries during blood withdrawal and 12/113 (10.6\%) while handling instruments (Table 2). Hollow-bore needle was the most common instrument causing 91/113 (80.5\%) of sharp instrument injuries followed by 61/113 (28\%) of injuries by intravenous catheters and 30/113 (14\%) injuries by scalpels respectively (Fig. 3).

\section{Nursing Students}

Out of 50/68 (73.5\%) of the sharp instrument injuries among nursing students occurred during intramuscular or intravenous injection followed by 11/68 (16.1\%) during blood withdrawal procedure (Table 2). Hollowbore needle was the common instrument causing 55/68 (80.8\%) of the injuries among the nursing students (Fig. 4).

\section{RATE OF REPORTING AND MANAGEMENT}

Among the 412 health care students who had experienced sharp instrument injuries in the past 1 year, 319 (77.4\%) of the students did not report the incident of the injury. Of the

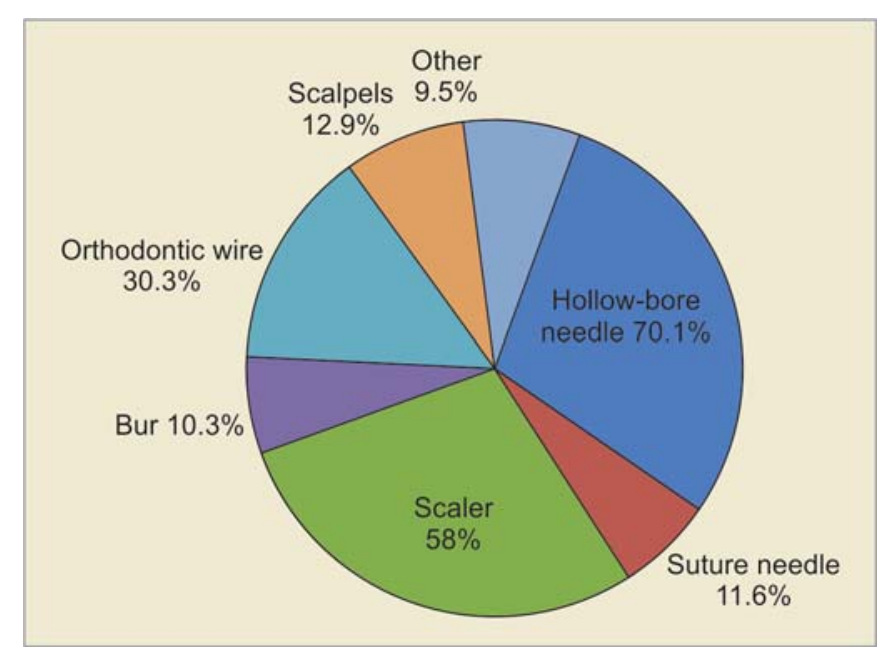

Fig. 2: Instruments causing sharp injuries in dental students

\begin{tabular}{|c|c|c|c|c|c|c|c|}
\hline \multirow{2}{*}{$\begin{array}{l}\text { Prevalence of sharp } \\
\text { instrument injuries }\end{array}$} & \multicolumn{2}{|c|}{ Dental } & \multicolumn{2}{|c|}{ Medical } & \multicolumn{2}{|c|}{ Nursing } & \multirow[t]{2}{*}{$p$-value } \\
\hline & $N$ & $\%$ & $N$ & $\%$ & $N$ & $\%$ & \\
\hline \multicolumn{8}{|c|}{ 1. Cases of sharp instrument injury } \\
\hline Yes & 231 & 75.4 & 113 & 48.7 & 68 & 76.4 & $0.00^{*}$ \\
\hline No & 75 & 24.5 & 119 & 51.2 & 21 & 23.5 & \\
\hline \multicolumn{8}{|c|}{ 2. Episodes of sharp instrument injury } \\
\hline One & 76 & 32.9 & 44 & 38.9 & 15 & 22 & $0.00^{*}$ \\
\hline Two & 75 & 32.4 & 47 & 41.5 & 41 & 60.2 & \\
\hline More than two & 80 & 34.6 & 22 & 19.4 & 12 & 17.6 & \\
\hline
\end{tabular}

*Highly significant ( $p$-value $<0.001)$ 


\begin{tabular}{|c|c|c|c|c|c|c|c|}
\hline \multirow[t]{2}{*}{ Type of procedure } & \multicolumn{2}{|c|}{ Dental } & \multicolumn{2}{|c|}{ Medical } & \multicolumn{2}{|c|}{ Nursing } & \multirow{2}{*}{$p$-value } \\
\hline & $N$ & $\%$ & $N$ & $\%$ & $N$ & $\%$ & \\
\hline Handling instruments & 65 & 28.1 & 12 & 10.6 & 5 & 7.3 & $0.00^{*}$ \\
\hline $\begin{array}{l}\text { Local anesthetic/ } \\
\text { intravenous/ } \\
\text { intramuscular injection }\end{array}$ & 121 & 52.3 & 70 & 61.9 & 50 & 73.5 & \\
\hline Wound suturing & 7 & 3 & 10 & 8.8 & 2 & 2.9 & \\
\hline Blood withdrawal & 0 & 0 & 21 & 18.5 & 11 & 16.1 & \\
\hline Scaling and polishing & 38 & 16.4 & 0 & 0 & 0 & 0 & \\
\hline
\end{tabular}

*Highly significant ( $p$-value $<0.001$ )

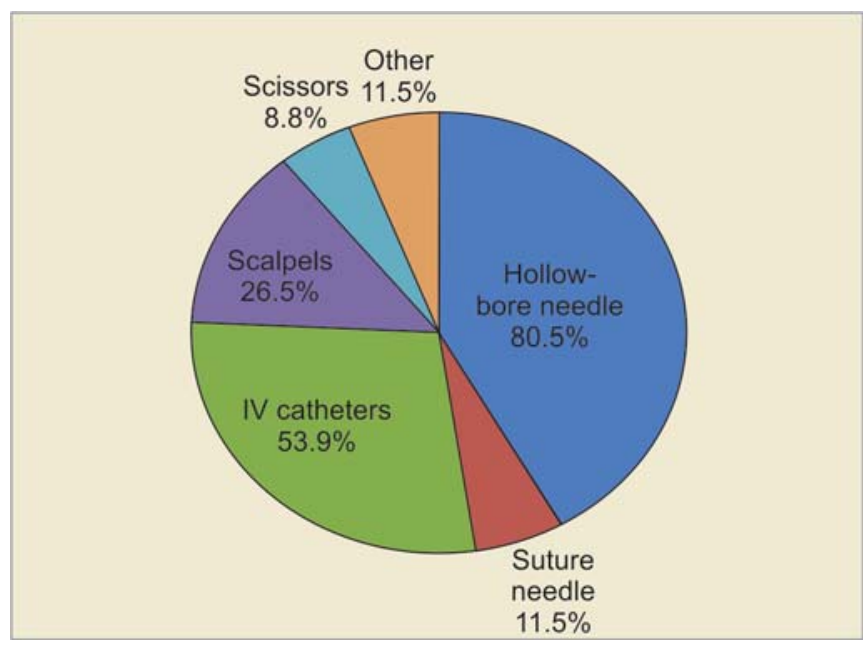

Fig. 3: Instruments causing sharp injuries in medical students

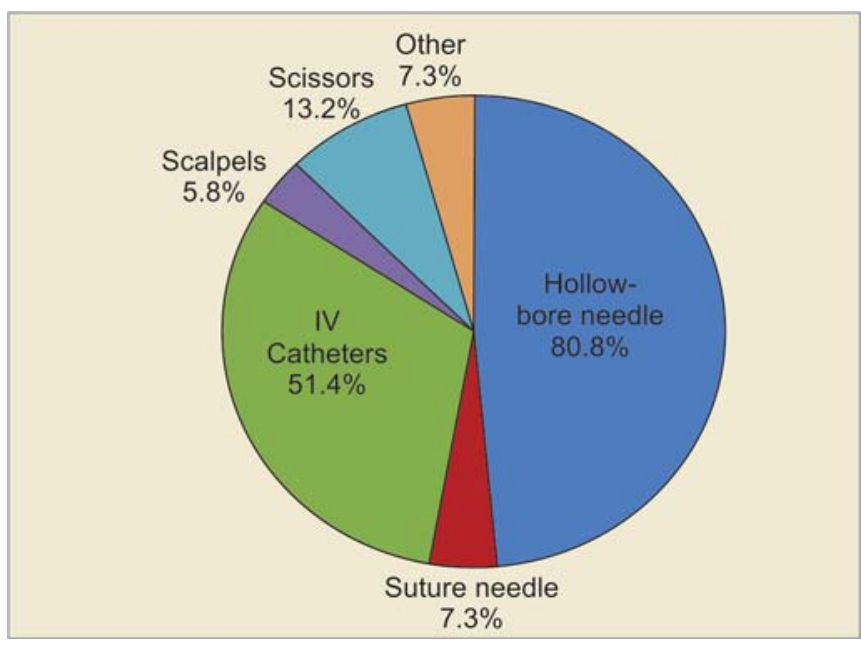

Fig. 4: Instruments causing sharp injuries in nursing students

319 students who did not report the incident of injury, 153 (47.9\%) students did not know how to report the injury followed by 108 (33.8\%) students thought that the injury was only minor so it was not to be reported. The other reasons for not reporting are given in Table 3. It was also found that $174 / 412$ (42.2\%) of the injuries had occurred while working on a patient in the clinical setting.

Only 142/412 (34.4\%) of the health care students had taken postexposure prophylaxis (PEP) after the injury.
A total of 234/412 (37.3\%) of the students had received PEP for hepatitis B and 135/627 (21.5\%) had received PEP for tetanus.

The health status of the students after the sharp instrument injury was found to be normal in 349/412 (84.7\%) students whereas 62/412 (15\%) students suffered from mental distress. None of the students had reported of chronic illness following sharp instrument injuries in this study.

\section{KNOWLEDGE OF SHARP INSTRUMENT INJURIES AND PROTECTIVE MEASURES TO AVOID SHARP INSTRUMENT INJURIES}

In the present study, only 250/627 (39.8\%) of the health care students could correctly define sharp instrument injury. Among all health care students who participated in this study, needle recapping was practiced by 594/627 (94.7\%) of students. Majority of the students 352/627 (56.1\%) used both hands to recap needles whereas 242/627 (38.5\%) used one hand 'scoop' technique. Only 33/627 (5.2\%) students avoided recapping needles. A total of 209/627 (33.3\%) of the students always use a sharps container to dispose the sharp instrument after use whereas 239/627 (38.1\%) leave the sharp instrument on the working tray which creates potential hazards for the workers involved in waste disposal. Protective measures to avoid sharp instrument injuries, such as wearing gloves were practiced by $606 / 627$ (96.6\%) of the health care students. Single glove technique was found to be commonly practiced by 593/627 (94.5\%) of the students followed by use of facemask by 327/627 (52.1\%) students and protective eyewear by only 95/627 (15.1\%) of the health care students.

\section{DISCUSSION}

Out of 627 health care students who completed the questionnaire, $48.8 \%$ were dental students, $37 \%$ were medical students and $14.2 \%$ were nursing students. The questionnaire was completed by $4.8 \%$ second year students, 
Table 3: Information regarding demographic profile, rate of reporting and management, knowledge about sharp instrument injuries and protective measures taken to avoid them by health care students

$\mathrm{N}$

1. Demographic profile:

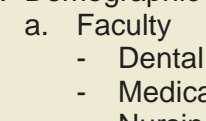

edical

b. Academic year

- Second year

- Third year

- Fourth year

- Internship

Age

Postgraduation

- $18-21$

- 22-24

- $25-29$

d. Gender

- Male

- Female

2. Rate of reporting and management

a. Did you report the incident of sharp instrument injury?

- Yes

- No

b. Reason for not reporting the incident of sharp instrument injury

- The instrument or needle was unused

- I did not know how to report it

- It was only minor, so I did not worry

- I was too embarrassed to report it

c. When did you experience the sharp instrument injury?

- While working on a patient

- Other

d. What was your health status after the sharp instrument injury?

- Normal

- Mental distress

- Chronic illness

e. Did you take PEP after the sharp instrument injury?

- Yes

- No

f. For which of the following did you take PEP?

i. Hepatitis B

- Yes

- No

ii. Tetanus

- Yes

- No

iii. HIV

- Yes

- No

3. Knowledge of sharp instrument injuries and protective measures taken to avoid them:

a. Definition of sharp instrument injuries

- Correct

- Incorrect

b. What protective measures do you take to avoid sharp instrument injuries?

- Gloves

- Facemask

- Eye protection

Other

c. Which glove technique so you use?

- Single glove technique

- $\quad$ Double glove technique

d. Do you recap needles?

- Yes

- No

e. Which technique do you use to recap needles?

- One hand 'scoop' technique

- Two hands to recap needles

f. Method of disposing sharp instruments

- Leave it on the working tray

- Place the instrument in a sharp container

- Throw the needle/sharp instrument in garbage 
22.3\% third year students, 34.4\% fourth year students, $29.7 \%$ interns and $8.8 \%$ postgraduate students respectively. The mean age of the students was 22.17 years ( \pm standard deviation, 1.870). Majority (75.6\%) of the health care students in the Mahatma Gandhi Mission's Campus were females.

Sharp instrument injuries are a major concern among health care students during their clinical training. The first case of needle-stick injury was reported in $1828 .{ }^{10}$ In the present study, majority of the cases of sharp instrument injuries were $76.4 \%$ among nursing students followed by $75.4 \%$ among dental students and $48.7 \%$ among medical students respectively. In a study conducted in Western Ontario University, Canada, nonsterile occupational injuries were reported by $82 \%$ of the dental students, $57 \%$ of the medical students and $27 \%$ of the nursing students respectively. ${ }^{11}$ Similar results were reported in a study by Askarian et al in which $73.7 \%$ of the dental students and $72.1 \%$ of the medical and midwifery students had experienced needle-stick injuries. ${ }^{12}$

Hollow-bore needles are devices which have commonly been associated with transmission of blood-borne infections because a larger volume of blood remains inside the bore of the needle as compared to solid core needle, such as suture needle. ${ }^{13}$ In our study, dental students most frequently reported $70.1 \%$ of the sharp instrument injuries by a hollowbore needle followed by $58 \%$ of the injuries by scaler and $30.3 \%$ of the injuries by orthodontic wire. Hollow-bore needle was also the most common cause of sharp instrument injuries among medical and nursing students followed by intravenous catheters. Similar study in Malaysia (2012) showed that $97 \%$ of the injuries were caused by hollowbore needles among medical students. ${ }^{14}$ In an Australian study, $29.2 \%$ of the sharp instrument injuries were caused by glass item and $24.4 \%$ by a hollow-bore needle. ${ }^{15}$ It has been shown that lack of experience in many procedures, insufficient training, work load and fatigue leads to sharp instrument injuries. ${ }^{16}$

In our study, the most common procedure associated with $52.3 \%$ of the sharp instrument injuries was local anesthetic injection among dental students followed by $28.1 \%$ of the injuries while handling instruments and $16.4 \%$ while scaling and polishing. Intramuscular or intravenous injection was found to be the common procedure causing sharp instrument injuries in $61.9 \%$ of the injuries among medical students and $73.5 \%$ of the injuries among nursing students respectively. A study done by Askarian et al also showed that such injury occurred during local anesthetic injection procedure in $29.8 \%$ of the dental students and during intramuscular and intravenous injection in 61.9\% medical students and 73.5\% nursing students respectively. ${ }^{16}$ Similarly, in a French study, drawing arterial blood was responsible for $44 \%$ of all exposure incidents. ${ }^{17}$ Our study showed that $42.2 \%$ of the injuries occurred while working on a patient in the clinical setting which is similar to the study in Suez Canal University Hospital (42.2\%). ${ }^{18}$

Unsafe handling practices of needles prior to disposal e.g. two-hand recapping (Fig. 5), needle flexing and needle breaking increase the risk of occupational exposure to sharp instrument injuries. According to Occupational Safety and Health Administration (OSHA)'s blood-borne pathogen standards (1996), needle recapping is prohibited to reduce the risk of transmission of blood-borne pathogens. ${ }^{19}$ In our study, $94.7 \%$ of the health care students recapped needle. In a study, Shariati et al showed that $92.9 \%$ of the medical interns frequently recapped contaminated needles. ${ }^{20}$ Similar results have been shown in a study by Hashemipour and Sadeghi in which $67.4 \%$ of the students recapped needles after use. ${ }^{10}$ Dentists and dental students are required to give multiple injections during the course of a patient's treatment which places them at a high-risk of sustaining sharp instrument injury. In these situations, one handed 'scoop' technique is recommended for recapping needle followed by immediate disposal of the needle in a sharps container after use. Proper training of the health care students through comprehensive educational programs and adoption of safety engineered devices have been effective in decreasing the incidence of sharp instrument injuries at some health care institutions. $^{11}$

Reporting of the incidents of sharp instrument injuries is important to ensure appropriate counseling and treatment of the health care students. In this study, $77.4 \%$ of the health care students did not report these injuries and the most

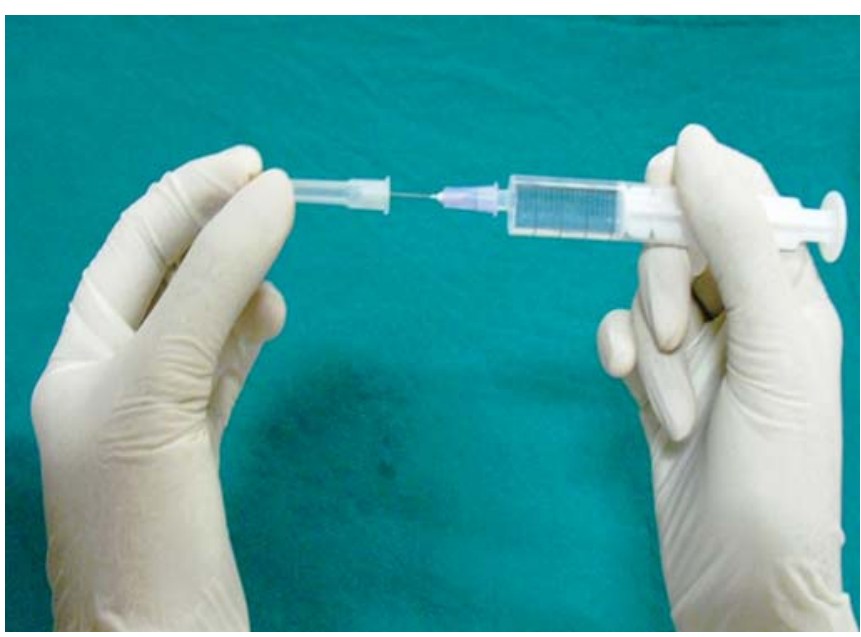

Fig. 5: Two-hand method of needle recapping (not recommended) 
common reason for not reporting was the lack of knowledge among the students about how the injury had to be reported. Results of the above study are in agreement with studies done by Khader et al (22.1\%) and Clarke et al (29\%). ${ }^{21,22}$ The higher level of under-reporting indicates the need for the formation of a reporting management and education regarding the importance of reporting all percutaneous injuries. The health status after the injury was found to be normal in $84.7 \%$ of the health care students. However, the psychological stress and emotional impact after an injury can affect the students performance and career if an infection results.

It was also disturbing that only $34.4 \%$ of the health care students had taken postexposure prophylaxis after the injury and 37.3\% had received PEP against HBV and only 21.5\% had received PEP for tetanus in our study. Among Taiwanese nursing students, vaccination against HBV was lacking in $47.6 \%$ of the nurses. ${ }^{23}$ However, the effectiveness of the vaccination is the most significant factor that needs to be tested among the health care students. PEP for HBV-positive sources for exposed health care students who are anti-HBs negative warrants hepatitis $B$ vaccination and a full course of passive immunization with hepatitis B immunoglobulin preferably within 24 hours. $^{24}$ PEP for health care students who experience sharp instrument injuries from HIV-positive sources includes 2 or 4 anti-retrovirals which should be initiated within 1 to 2 hours postexposure. ${ }^{24}$ The risk of transmission depends on the degree of exposure, the type of instrument used and the evaluation of the source patient. Hepatitis B is more transmissible than human immunodeficiency virus and 10 times more transmissible than $\mathrm{HCV}^{25}$ Therefore, it is universally recommended that health care students and professionals should be immunized against HBV. The incubation period for tetanus varies from 1 to 2 days to a month or more; most cases have onset of symptoms within 7 to 14 days of the initial injury. ${ }^{26}$ If the history of the last booster of tetanus was greater than 10 years, then tetanus toxoid ( $\mathrm{Tt}$ ) should be administered and if the history demonstrates that the last immunization was over 10 years ago, then tetanus immune globulin (TIG) should be administered. ${ }^{26}$

In 1983, the Centers for Disease Control (CDC) made the first recommendations for the prevention of exposure to blood and body fluids through the use of universal precautions. These guidelines emphasize the use of protective barriers, such as gloves, facemasks, protective clothing, eyeglasses, etc. to avoid the risk of transmission of occupational and nosocomial infections among health care workers. In the present study, it was found that $96.6 \%$ of the students wore gloves, 52.1\% wore facemask and only $15.1 \%$ always wore eye protection during clinical procedures. However, double glove technique was practiced by only $5.4 \%$ of the students. In the study by Meunier et al found that almost $50 \%$ of the medical students in Strasburg do not use two gloves and the reasons stated were decrease in hand sensitivity and lack of belief in its benefits. ${ }^{27}$ In a study by the Washington University, $86 \%$ of the students reported of always using double gloves in the operating room and $90 \%$ reported always using eye protection. ${ }^{28}$ Among the health care students, 33.3\% of the students always used a sharps container for disposing the sharp instrument after use whereas 38.1\% leave the sharp instrument on the working tray. Improper disposal of needles and other sharp instrument creates potential hazards not only for the students but also for the workers involved in waste disposal (Fig 6). Similar results were found in a study in Suez Canal University in Egypt, which showed that only $16.6 \%$ of the workers safely discarded the sharp objects. ${ }^{18}$ Double gloving technique should be considered by institutional authorities while implementing sharp injury prevention programs as it has shown to decrease the risk of internal glove perforation and hence potential of exposure to cross-infection. ${ }^{29}$ Strict adherence to universal precautions among health care students is imperative to avoid sharp instrument injuries.

One limitation of the present study was the recall bias whereby the health care students might not have remembered or not reported the actual incident of sharp instrument injury that they had in the past 1 year.

\section{CONCLUSION}

1. The demographic profile of the dental, medical and nursing student revealed that majority of the students

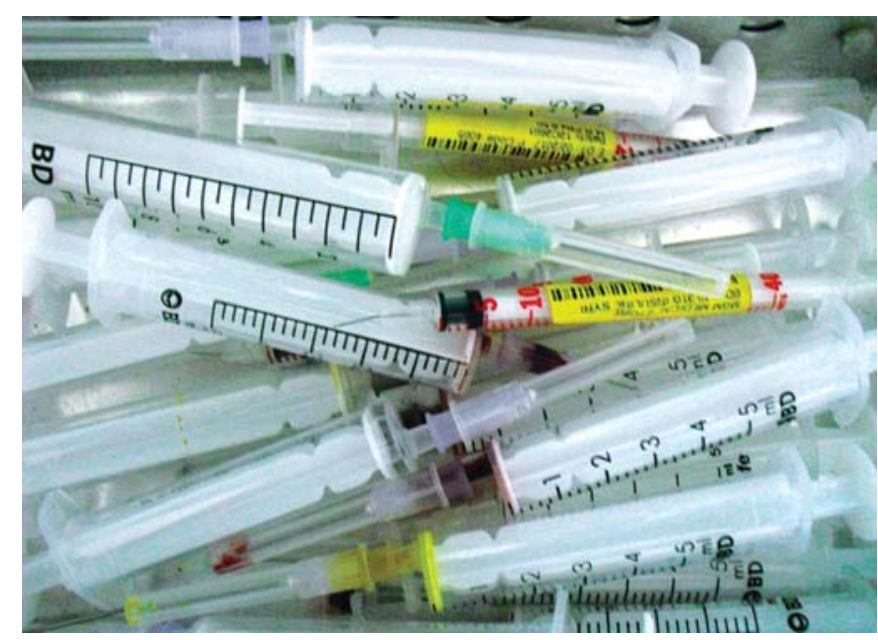

Fig. 6: Improper method of disposing needles 
were female and the mean age was 22.17 years ( \pm standard deviation, 1.870).

2. The prevalence of sharp instrument injury was found to be the highest among nursing students, followed by dental and medical students respectively. Nursing and dental students start treating patients during their clinical training as an undergraduate. However, this is not the case with medical students who begin treating patients only in internship which indicates the lower prevalence of sharp instrument injuries among medical students as compared to dental and nursing students. Therefore, this study revealed that dental and nursing students were at a higher risk of being exposed to sharp instrument injuries as compared to medical students.

3. In our study, occupational exposure to sharp instrument injuries were mostly caused by hollow-bore needle and the procedure most commonly associated with the injury was administration of local anesthetic or intramuscular or intravenous injection among all the health care students. Majority of the health care students recapped needles and the two hand technique of needle recapping was predominantly practiced. Therefore, lack of experience and improper training contribute to an increase risk to sharp instrument injuries among the students.

4. The rate of reporting of incidents of sharp instrument injuries among all the health care students was found to be low. Similarly, PEP for hepatitis B and tetanus had not been taken by majority of the students which indicates a lack of awareness regarding the significance of PEP.

5. In the present study, knowledge about sharp instrument injuries was poor and protective measures taken to prevent such injuries were inadequate among the students.

6. Therefore, recommendations to avoid sharp instrument injuries among health care students are as follows:

- Effective training and continuous education through seminars and workshops should be conducted among all health care students to increase the awareness about Universal Precautions and Infection Control and reduce the occupational hazard of sharp instrument injuries.

- Safer work practice and proper instrumentation is essential to avoid such injuries. It is imperative to effectively train all the students regarding proper use of instruments, one hand 'scoop' method of recapping needle, safe disposal of sharp instruments in a rigid sharp container and immediate discarding of needles in a needle incinerator during their clinical training (Fig. 7).

- Also, the use of safety engineered devices, such as blunt suture needles, round tipped scalpel blades instead of pointed tipped scalpel needleless intravenous systems and safety syringes should be incorporated into practice in the clinical training in order to prevent sharp instrument injuries.

- A reporting center should be established by the institutional authorities for registering, reporting and receiving PEP for sharp instrument injuries. This will monitor the occupational risk factors, prevalence of these injuries and the effectiveness of intervention strategies in the clinical training of the health care students which would guide the institutional authorities to make recommendations for new practices and safer devices to prevent the reoccurrence of such injuries.

- A PEP program should be established and a policy should be formulated at the institutional level which would make it mandatory for all health care students to report and record sharp instrument injuries at the reporting center and would also perform baseline test for both the health care student and the patient with administration of prophylaxis if required.

- Immunization against HBV should be made mandatory for all health care students before they start their clinical training.

- Use of double glove technique during clinical training should be made compulsory and encouraged by the institutional authorities.

\section{SUMMARY}

The present study was conducted among the dental, medical and nursing students in the Mahatma Gandhi

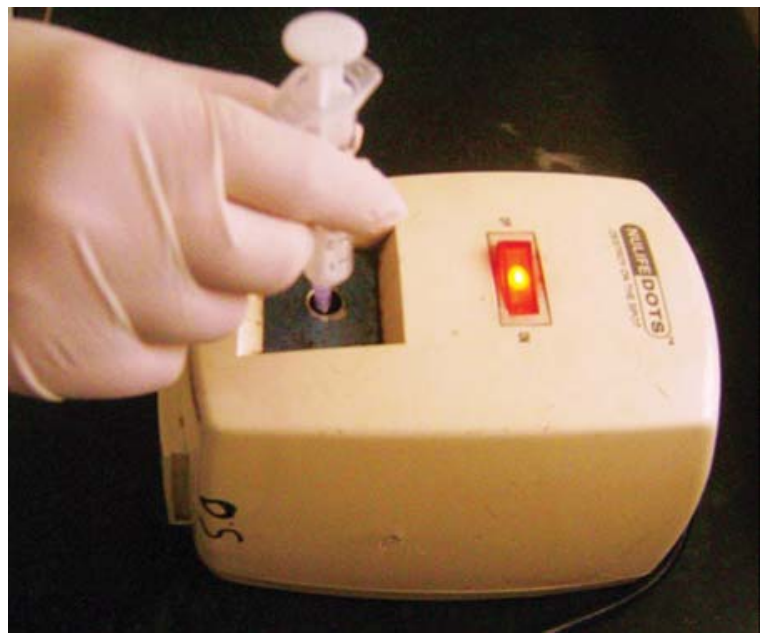

Fig. 7: Needle incinerator 
Mission's Campus, Navi Mumbai, India. This study showed that the prevalence of sharp instrument injuries was the highest among nursing students followed by dental and medical students respectively. Improper handling and disposal of sharp instruments have been the most common risk factors associated with these injuries. The two major areas of concern is the absence of a reporting center and immunization against hepatitis $B$ among the health care students which requires immediate attention by the institutional authorities. Also, negligence in adherence to universal precautions has been commonly shown in this study. Therefore, we recommend that a committee should be established by the institutional authorities which would form a reporting center to record sharp instrument injuries and also administer postexposure prophylaxis in required cases. Similarly, continuous education programs and seminars should be carried out to increase the awareness of occupational exposure to sharp instrument injuries among the students.

\section{ACKNOWLEDGMENT}

The authors would like to thank Mr Pandurang V Thatkar, Assistant Professor cum Biostatistician, Mahatma Gandhi Mission's Medical College, Kamothe, Navi Mumbai, for his assistance in the statistical analysis.

\section{REFERENCES}

1. Morgan Dr. Missing the point: A review of needle stick injury and occupational risks from blood-borne viruses. J Am Bio Safety Assoc 2000;5(2):47-53.

2. Collins $\mathrm{CH}$, Kennedy DA. Microbiological hazards of occupational NSI and sharps injuries. J Appl Bacteriol 1987;62:385-402.

3. Panlilio AL, Cardo DM, Campbell S, Srivastava PU, Jagger H, Orelien JG, et al. Estimate of the annual number of percutaneous injuries in US healthcare workers (Abstract S-T2-01). In: Program and abstracts of the 4th International Conference on Nosocomial and Healthcare-Associated Infections; Atlanta 2000 March 5-9:61.

4. Askarian M, Ghavanini AA. Survey on adoption of measure to prevent nosocomial infection by anesthesia personnel. East Med Health J 2002;8:416-21.

5. Johnson G. International hospital federation reference book 2007/2008;89-94.

6. Pery J, Parker G, Jagger J. EPINET report: 2003 percutaneous injury rates. Adv Exposure Prev 2005;7:2-45.

7. Jayanth ST, Kirupakaran H, Brahmadatan KN, Gnanaraj L, Kang G. Needle stick injuries in a tertiary care hospital. Indian J Med Microbiol 2009;27:44-47.

8. Rele M, Mathur M, Turbadkar D. Risk of needle stick injuries in health care workers-a report. Indian J Med Microbiol 2002;20:206-07.
9. Hashemipour M, Sadeghi A. Needlestick injuries among medical and dental students at University of Kerman. A Questionnaire Study. J Dent 2008;5(2):71-76.

10. Whitby RM, McLaws ML. Hollow-bore needlestick injuries in a tertiary teaching hospital: Epidemiology, education and engineering. Med J Aust 2002;177(8):418-22.

11. McCarthy GM, Britton JE. A survey of final year dental, medical and nursing students. J Can Dent Assoc 2000 Nov; 66(10):561.

12. Askarian M, Malekmakan L, Memish ZA, Assadian O. Prevalence of needle stick injuries among dental, nursing and midwifery students in Shiraz, Iran. GMS Krankenhaushygiene Interdisziplinar 2012;7(1):Doc05.

13. Norsayani MY, Hassim NI. Study on incidence of needle stick injury and factors associated with this problem among medical students. J Occup Health 2003 May;45(3):172-78.

14. Swe KMM, Zin Thant, Bhardwaj A, Abas ABL, Barua A. The prevalence of needle sticks injury among medical students in melaka, Malaysia, A cross-sectional study. Eur J Scientific Research 2012;71(2):214-20.

15. Smith DR, Leggat PA. Needlestick and sharps injuries among Australian medical students. J UOEH 2005;1(27): 237-42.

16. Askarian M, Malekmakan L. The prevalence of needle stick injuries in medical, dental, nursing and midwifery students at the University Teaching Hospital of Shiraz, Iran. Indian J Med Sci 2006;60(6):227-32.

17. Keita-Perse O, Pradier C, Rosenthal E, Altare J, Cassuto JP, Dellamonica P. Hospital medical students: A population at risk for accidental exposure to blood. Presse Med 1998;7(27): 1723-26.

18. Fahim AE. Sharp devices injury among resident physicians and nurses in Suez Canal University Hospital. Suez Canal Univ Med J 2008;11(1):47-52.

19. O’Neil JT. The blood-borne pathogen standard: A pragmatic approach. New York: Van Nostrand Reinhold 1996.

20. Shariati B, Mahani AS, Oveysi T, Akhlaghi H. Accidental exposure to blood in Medical Interns of Tehran University of Medical Sciences. J Occup Health 2007;49:317-21.

21. Khader Y, Burgan S, Amarin Z. Self-reported needle-stick injuries among dentists in North Jordan. East Mediterr Health J 2009;15(1):185-89.

22. Clark SP, Rockett JL, Sloane DM, Aiken LH. Organizational climate, staffing and safety equipment as predictors of needle stick injuries and near misses in hospital nurses. Am J Infect Control 2002;30:207-16.

23. Shiao JS, McLaws ML, Huang KY, Guo YL. Student nurses in Taiwan at high-risk for needlestick injuries: Ann Epidemiol 2002;12:197-201.

24. Rodrigues C. Needle stick injuries and healthcare workersthe time to act now. Indian J Med Res 2010;384-86.

25. LaForce FM, Young LS, Bennett JV. Tetanus in the United States (1965-1966): Epidemiologic and clinical features. N Engl J Med 1969;280:569-74.

26. Rhee P, Nunley MK, Demetriades D, Velmahos G, Doucet JJ. Tetanus and trauma: Review and recommendations. J Trauma 2005;58(5):1082-88.

27. Meunier O, Almeida N, Hernandez C, Bientz M. Blood exposure accidents among medical students: Medecine et maladies infecc 2001;31(9):537-43. 
28. Patterson JM, Novak CB, Mackinnon SE, Ellis RA. Needlestick injuries among medical students. Am J Infect Control 2003;31: 226-30.

29. Smith DR, Muto T, Sairenchi T, Ishikawa $Y$, Sayama S, Yoshida A, et al. Hospital safety climate, psychological risk factors and needlestick injuries in Japan. Industrial Health 2010;48:85-95.

\section{ABOUT THE AUTHORS}

\section{Juveria Syed Ali Hussain (Corresponding Author)}

Intern, Department of Prosthodontics, MGM Dental College and Hospital, Kamothe, Navi Mumbai-410209, Maharashtra, India Phone: 9870445578, e-mail: juveriaali@yahoo.com

\section{Sabita M Ram}

Dean, Professor and Head, Department of Prosthodontics, MGM Dental College and Hospital, Navi Mumbai, Maharashtra, India

\section{Jyotsna Galinde}

Professor and Head, Department of Oral and Maxillofacial Surgery, MGM Dental College and Hospital, Navi Mumbai Maharashtra, India

\section{Ranganatha Rao K Jingade}

Reader, Department of Prosthodontics, MGM Dental College and Hospital, Navi Mumbai, Maharashtra, India 